\title{
Melhoramento de campo nativo com uso de calcário e gesso agrícola nos Campos de Cima da Serra/RS
}

\author{
Improvement of native grassland fields with use of lime and agricultural gypsum in \\ "Campos de Cima da Serra"/RS
}

\begin{abstract}
João Claudio Dalmina ${ }^{1 *}$ (ORCID 0000-0003-2335-2554), Guilherme de Lima Teixeira 2 (ORCID 0000-0001-7056-5494), Jhullia Andolfato Matté 1 (ORCID 0000-0002-4204-2837), Douglas Antonio Velho 2 (ORCID 0000-0001-8112-7190), Vinícius Rissardi de Vargas 2 (ORCID 0000-0003-4244-450X), Elaine Damiani Conte 2 (ORCID 0000-0002-6523-7100)
\end{abstract}

'Universidade do Estado de Santa Catarina, Lages, SC, Brasil. *Autor para correspondência: joaocdalmina@hotmail.com

${ }^{2}$ Universidade de Caxias do Sul, Vacaria, RS, Brasil.

Submissão: 15/02/2021 | Aceite: 14/10/2021

\begin{abstract}
RESUMO
O objetivo deste trabalho foi verificar o efeito da aplicação de calcário, em doses superiores às recomendadas, e de gesso agrícola na produtividade e teor de macronutrientes do campo nativo na região dos Campos de Cima da Serra - RS. O experimento foi realizado em área de pastagem nativa, localizado em Vacaria - RS. O experimento foi disposto em blocos completamente casualizados alocados em parcelas subdivididas, com quatro repetições. Conduzido em esquema fatorial $3 \times 2$ : sendo três doses de calcário ( 0 ; 3,0 e 5,0 ton ha-1, visando atingir a saturação por bases de $65 \%$ e 5,0 ton ha-1 ${ }^{-1}$, visando atingir uma saturação por bases de $75 \%$ ) e duas doses de gesso ( 0 e 2,0 ton ha $\left.{ }^{-1}\right)$, aplicados superficialmente. O gesso agrícola foi aplicado aleatoriamente em uma das subparcelas. Ao final de cada estação climática foram realizadas avaliações da produção de massa de forragem e teor de macronutrientes, na matéria seca da parte aérea, em duas amostras coletada de uma área de $0,25 \mathrm{~m}^{2}$ por parcelas, através do corte da parte aérea "rente ao solo". A produção de matéria seca do campo nativo no outono, inverno e primavera, apresentou incremento significativo com a aplicação de 5 ton ha-1, sem haver influência no verão. A aplicação de calcário no solo aumentou o teor de nitrogênio e potássio no tecido foliar do campo nativo no período do outono e de cálcio na primavera. A aplicação de gesso agrícola aumentou a produção de matéria seca apenas na primavera e reduziu os teores de magnésio no inverno. Portanto, os resultados demonstram, o potencial de uso do calcário em doses superiores as recomendadas atualmente e do gesso agrícola para aumento da produção de forragem e qualidade das forragens naturais nas épocas avaliadas por este presente trabalho.
\end{abstract}

PALAVRAS-CHAVE: calagem, forragem, nutrição.

\section{ABSTRACT}

The objective of this work was to verify the effect of the application of lime in doses higher than those recommended and of agricultural gypsum on the productivity and macronutrient content of the native field in the "Campos de Cima da Serra" region (Southern Brazil). The experiment was conducted in a native pasture located in Vacaria municipality (Rio Grande do Sul state). The experiment was arranged in randomized blocks allocated in split plots, with four replications each. Conducted in a $3 \times 2$ factorial scheme: three doses of limestone $(0,3$, and 5 ton ha- 1 , aiming to reach a base saturation of $65 \%$ and 5.0 ton ha- 1 , aiming to reach a base saturation 75\%) and two doses of gypsum (0 and 2.0 ton ha-1), applied superficially. In addition, agricultural gypsum was randomly applied to one of the subplots. At the end of each climatic season, evaluations of forage mass production and macronutrient content were carried out in dry shoot matter in two samples collected from an area of $0.25 \mathrm{~m} 2$ per plot by cutting the aerial part "close to the ground". The production of dry matter in the native field in autumn, winter and spring showed a significant increase with the application of 5 ton ha $^{-1}$, with no influence in summer. Furthermore, the application of lime in the soil increased the nitrogen and potassium content in the leaf tissue of the native field in the autumn period. Interestingly, the same happens to calcium in the spring. On the other hand, the application of agricultural gypsum increased dry matter production only in spring and reduced magnesium contents in winter. Therefore, the results demonstrate the potential of using limestone in doses higher than those currently recommended and agricultural gypsum to increase natural forage production and their quality at time intervals evaluated in this work.

KEYWORDS: liming, forage, nutrition. 


\section{INTRODUÇÃO}

Os vastos campos situados no Sul do Brasil, Argentina e Uruguai, vem sofrendo transformações, estas de alto impacto. Além de alterar suas paisagens típicas, ameaça sua biodiversidade. Extensas áreas já desapareceram e outras correm esse mesmo risco, isso se deve à grande demanda por espaços cultiváveis. Nos três estados do Sul do Brasil, estima-se que esses campos já estejam reduzidos a baixo de $40 \%$, no que reflete em cerca de $10 \mathrm{mil} \mathrm{km}^{2}$ a menos de sua vegetação original, este levantamento teve início no ano de 2010 e o dado mais recente foi coletado em 2018 (WEISSHEIMER 2015, IBGE 2020).

O estado do Rio Grande do Sul, situado no sul do Brasil, abrange uma superfície de aproximadamente $280.000 \mathrm{~km}^{2}$, apresenta grandes extensões de campos. Encontrando-se em diferentes biomas, parte do Estado está incluído no bioma Mata Atlântica e no bioma Pampa. Os Campos de Cima da Serra situam-se no Bioma Mata Atlântica, no qual está região abrange uma área de $10,4 \mathrm{~km}^{2}$. Está região tem características únicas com clima frio da região aliado à alta precipitação pluviométrica e altitude elevada desenvolveu muitos endemismos, ou seja, as plantas evoluíram e se adaptaram a este ambiente e se tornaram exclusivas desta região (BOLDRINI 2009).

O campo nativo é de vital importância para o segmento pecuário no Rio Grande do Sul, sendo evidenciado por sua grande extensão, da qual se destaca a presença de formações campestres, que possui vasta diversidade de espécies, cuja fisiologia está ligada aos diversos tipos de solo e condições climáticas predominantes em cada região fisiografia. No entanto, o sistema de produção baseado no campo nativo tem sido sinônimo de produção extensiva, caracterizado pela baixa produtividade e, consequentemente, baixa rentabilidade (CARVALHO et al. 1998).

O declínio na produtividade das pastagens nativas é uma das principais causas da baixa lucratividade e competitividade entre os sistemas de produção de bovinos a pasto. As regiões tropicais apresentam dois períodos de produção, sendo um de alta produção forrageira, também compreendida como o período das águas e outro de baixa produção forrageira, podendo ser chamado de período seco. Na região Sul do Brasil, a baixa produção forrageira no período de inverno está mais relacionada à queda na temperatura, do que ao déficit hídrico, sendo que a queda na temperatura faz com que os teores de lignina dos pastos aumentem, se tornando menos palatáveis para os animais (MOREIRA et al. 2001).

Os solos da região dos Campos de Cima da Serra apresentam caráter fortemente ácido e baixa fertilidade natural (CONTE et al. 2016). A aplicação de calcário e fertilizantes, a introdução de espécies e a roçada melhoram a qualidade da forragem (HERINGUER \& JAQUES 2002). Quando as condições de fertilidade do solo são baixas, o uso de fertilizante complementa os efeitos benéficos do manejo correto das pastagens naturais (NABINGER et al. 2009). A adubação de pastagem tem o objetivo de aumentar tanto a quantidade como a qualidade das pastagens, com isso, pode-se incrementar a produtividade animal tanto em ganho de peso individual quanto ganho por área (STELLA et al. 2013) e, desta forma, possibilita o abate precoce de novilhos, com satisfatório grau de acabamento (FERREIRA et al. 2011). De modo similar, em pastagens naturais, o uso de insumos proporciona incremento na produção de forragem (AVILA et al. 2019) A melhoria na fertilização pode ajudar a estabilizar a qualidade da forragem ao longo do ano, principalmente por meio de seu efeito sobre a participação de espécies de inverno, proporcionando um aumento em algumas frações da composição química da forragem nesta temporada (ELEJALDE et al. 2012).

A calagem é responsável pela melhoria das condições químicas nas camadas superficiais do solo e tem função de fornecer cálcio e magnésio para as plantas e neutralizar a acidez. A gessagem aumenta o teor de cálcio e enxofre e reduz a toxicidade do Al no solo, mas não o neutraliza. Uma prática não substitui a outra, sendo que calcário e gesso são insumos complementares e não substitutivos (ARAÚJO 2017). A calagem na superfície, apresenta eficiência na correção da acidez de camadas superficiais e do subsolo, mas a reação do calcário aplicado superficialmente é mais rápida em condições de maior acidez do solo (CAIRES et al. 2002).

De acordo com o manual de adubação e calagem para os solos do Rio Grande do Sul e Santa Catarina (CQFS-RS/SC 2016), a recomendação de calagem para campo nativo deve ser calculada para atingir $45 \%$ de saturação de bases. Entretanto, para a maioria das plantas cultivadas, são recomendadas doses para atingir saturação superiores, para o máximo potencial produtivo das culturas. Já para a gessagem, CAIRES \& GUIMARÃES (2016), propuseram uma recomendação para culturas anuais no sul do Brasil que visa elevar a saturação por Ca na CTCe (capacidade de trocas de cátions efetiva) do subsolo (20 $-40 \mathrm{~cm}$ ) a $60 \%$. Entretanto, não há uma recomendação específica de gesso para utilização em campo nativo.

São diversos fatores, os quais variam a composição mineral das plantas alguns elementos nas plantas são considerados moveis nos tecidos das plantas como é o exemplo do nitrogênio, fósforo, potássio 
e magnésio, enquanto que cálcio é relativamente imóvel, concentrando-se nos órgãos mais novos (CORSI \& SILVA 1985).

Portanto, este trabalho teve como objetivo avaliar o efeito da aplicação de calcário e gesso agrícola na produção e teores de macronutrientes do campo nativo na região dos Campos de Cima da Serra, RS.

\section{MATERIAL E MÉTODOS}

O experimento foi realizado em campo nativo, nas coordenadas $28^{\circ} 34^{\prime} \mathrm{S}$ e $50^{\circ} 56^{\prime} \mathrm{O}$, localizada no município de Vacaria, região dos Campos de Cima da Serra do Rio Grande do Sul. O campo nativo da região faz parte do bioma Mata Atlântica (BOLDRINI 2009). O solo dominante nesta região é considerado como Latossolo Bruno. O clima é classificado como temperado (Cfb), segundo a classificação climática de Köppen-Geiger. $O$ trabalho foi conduzido nas diferentes estações do ano: outono, inverno, primavera e verão.

Antes da implantação do experimento, realizou-se a coleta de solo para a caracterização dos aspectos químicos, foram coletadas 24 subamostras de solo em toda área, onde o experimento foi instalado (0,06 ha), as quais formaram uma única amostra composta, para definição das doses de calcário e gesso agrícola nos tratamentos. Foi utilizado o trado tipo holandês, com diâmetro de $10 \mathrm{~cm}$ e profundidade de $0-$ $20 \mathrm{~cm}$ para a realização das coletas e análises, de acordo com TEDESCO et al. (1995).

Após a análise de solo, a amostra apresentou as seguintes características químicas na profundidade de 0-20 cm, expressa na tabela abaixo (Tabela 1).

Tabela 1. Características químicas do solo da área do experimento.

Table 1. Chemical characteristics of the soil in the experiment area.

\begin{tabular}{ccccccccccccc}
\hline \multicolumn{10}{c}{ Atributos Químicos } \\
\hline $\mathrm{pH}$ & SMP & $\mathrm{MO}$ & $\begin{array}{c}\mathrm{V} \\
---\end{array}$ & $\begin{array}{c}\mathrm{P} \\
-\mathrm{mg} \mathrm{dm}^{-3}-\end{array}$ & $\mathrm{S}$ & $\mathrm{CTCe}$ & $\mathrm{CTC}$ & $\mathrm{Ca}$ & $\mathrm{Mg}$ & $\mathrm{Al}$ & $\mathrm{H}+\mathrm{Al}$ \\
\hline 5,3 & 5,4 & 6,2 & 45,2 & 1,3 & 16,3 & 0,45 & 7,7 & 15,8 & 4,3 & 2,4 & 0,6 & 8,7 \\
\hline
\end{tabular}

MO: matéria orgânica; V: saturação de bases; P: fósforo; S: enxofre; K: potássio; CTCe: capacidade de troca de cátions efetiva; CTC: capacidade de troca de cátions a pH 7,0; Ca: cálcio; Mg: magnésio; Al: alumínio; H+Al: hidrogênio + alumínio.

O experimento foi conduzido em esquema fatorial $3 \times 2$, sendo três doses de calcário calcítico, com $94 \%$ de poder relativo de neutralização total (PRNT) $(0 ; 3,5$ e 5,0 ton ha-1) e gesso nas doses de 0 (zero) e 2 ton ha-1. O ensaio foi disposto em blocos completamente casualizados, alocados em parcelas subdivididas, com quatro repetições. As parcelas apresentaram dimensões de $10 \mathrm{~m} \times 5 \mathrm{~m}\left(50 \mathrm{~m}^{2}\right)$, subdivididas em duas subparcelas de $5 \times 5 \mathrm{~m}$, totalizando 24 subparcelas de $25 \mathrm{~m}^{2}$. As doses de calcário das parcelas foram obtidas através do método de saturação por bases $(\mathrm{NC}=[(\mathrm{V} 1-\mathrm{V} 2) / 100] \times \mathrm{CTC} \mathrm{pH} 7,0)$, visando atingir $65 \%$ e $75 \%$ de saturação por bases.

A aplicação de gesso agrícola ocorreu aleatoriamente, em uma das subparcelas, para cada dose de calcário. Para obtenção da dose de gesso agrícola foi utilizado o método de CAIRES \& GUIMARÃES

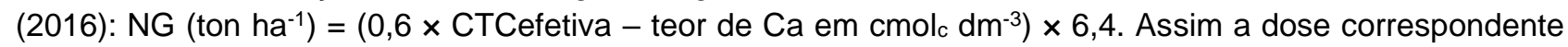
foi de 2 ton ha-1 de gesso agrícola e na subparcela com $25 \mathrm{~m}^{2}$, a dose foi de $5 \mathrm{~kg}$.

A área do experimento ficou sob pastejo de bovinos de corte durante os 145 dias após a aplicação dos tratamentos e, posteriormente, foi fechada visando a avaliação da produção de matéria seca do campo nativo, num ciclo de 12 meses (4 estações) na sequência: outono, inverno, primavera e verão.

As avaliações da produção e teor de macronutrientes na matéria seca da parte aérea foram realizadas em duas amostras, obtidas através do corte "rente ao solo", em uma área de $0,5 \times 0,5 \mathrm{~m}$ por parcelas, com o auxílio de uma máquina de cortar grama e uma caixa fechada apenas com as laterais totalizando $0,50 \mathrm{~m}^{2}$. A coleta foi realizada no final de cada estação nos mesmos locais.

As amostras coletadas foram encaminhadas para secagem em estufa de ventilação forçada de ar, a $65^{\circ} \mathrm{C}$ até obter massa constante (SILVA \& QUEIROZ 2006). Utilizando o valor do peso seco das amostras, foi calculado a matéria seca por hectare. Na sequência, as amostras de matéria seca foram homogeneizadas trituradas e determinados os teores de macronutrientes (nitrogênio, cálcio, magnésio, fósforo, potássio e enxofre) no tecido de acordo com MALAVOLTA et al. (1997).

Os resultados das avaliações foram submetidos à análise de variância e o efeito do calcário foi comparado pelo teste de Tukey $(p \leq 0,05)$ e o efeito da aplicação do gesso agrícola pelo teste $F(p \leq 0,05)$. 0 aplicativo estatístico utilizado foi o WinStat - Sistema de Análise Estatística, Versão 1.06. 


\section{RESULTADOS E DISCUSSÃO}

Os parâmetros avaliados neste trabalho não apresentaram interação calcário x gesso agrícola em todas as épocas avaliadas, e, portanto, serão discutidos de forma isoladas.

A produção de matéria seca do campo nativo no outono, inverno e primavera, apresentou incremento significativo com a aplicação de 5 ton ha-1 ${ }^{-1}$ dose necessária para elevação da saturação por bases a $75 \%$ (Tabela 2). No período do verão não houve diferença significativa na produção de matérias seca com a aplicação de calcário.

Tabela 2. Matéria seca do nativo nas quatro estações do ano com aplicação superficial de calcário no solo. Table 2. Dry matter of the native in the four seasons of the year with superficial application of lime in the soil.

\begin{tabular}{llllc}
\hline \multirow{2}{*}{$\left.\begin{array}{l}\text { Calcário } \\
\text { (ton ha }\end{array}{ }^{-1}\right)$} & Outono & Inverno & Primavera & Verão \\
\cline { 2 - 5 } & & \multicolumn{2}{c}{ Matéria seca $\left(\mathrm{kg} \mathrm{ha}^{-1}\right)$} \\
\hline 0,0 & $1973,3 \mathrm{~b}$ & $141,40 \mathrm{~b}$ & $719,80 \mathrm{~b}$ & $1919,40^{\text {ns }}$ \\
3,5 & $2246,0 \mathrm{ab}$ & $164,20 \mathrm{ab}$ & $909,80 \mathrm{ab}$ & 2049,20 \\
5,0 & $2624,4 \mathrm{a}$ & $300,80 \mathrm{a}$ & $1013,20 \mathrm{a}$ & 2309,00 \\
\hline CV $(\%):$ & 18,83 & 24,84 & 20,39 & 19,71 \\
\hline DP: & 21,03 & 5,84 & 8,98 & 20,62 \\
\hline
\end{tabular}

DP: Desvio padrão. Médias seguidas por letras diferentes, dentro da coluna, diferem significativamente no nível de probabilidade de $5 \%$ pelo teste de Tukey. ns = não significativo pelo teste $F(p \leq 0,05)$.

COSTA et al. (2012) observaram que a calagem incrementou significativamente os rendimentos de matéria seca de Brachiaria, tendo maior capacidade técnica para a produção de forragem na dose de 3.087 $\mathrm{kg} \mathrm{ha}^{-1}$. Segundo PAULETTI et al. (2014) a calagem faz com que aumente a produtividade de gramíneas e leguminosas, pelo fato da capacidade de troca de cátions e com isso sua absorção do solo pelas raízes das distintas famílias. Os resultados encontrados na produção de matéria seca confirmam uma resposta positiva do campo nativo às correções com calagem.

De acordo com ELEJALDE et al. (2012), a flutuação sazonal resulta tanto de alterações morfológicas das plantas em função de sua evolução fenológica quanto da substituição sazonal de espécies da flora. Em inverno vigoroso, muitas espécies perenes entram em período de repouso (dormência), retornando ao ciclo vegetativo anual tão logo as condições térmicas (climáticas) se tornem adequadas (BERGAMASCHI 2007). A ausência de respostas significativas da produção de matéria seca no verão pode ser atribuída a condição climática mais favorável para o desenvolvimento das espécies neste período mascarando uma melhoria nas condições químicas do solo e/ou a uma diminuição da sua eficiência devido ao tempo transcorrido entre a aplicação e a avaliação no verão.

Em relação a matéria seca do campo nativo com a aplicação de gesso agrícola, verificou-se aumento significativo apenas na primavera (Tabela 3), já para as demais estações do ano a aplicação não apresentou diferenças significativas.

Tabela 3. Matéria seca do campo nativo nas quatro estações do ano com aplicação superficial de gesso agrícola no solo.

Table 3. Dry matter of the native field in the four seasons with superficial application of agricultural plaster on the soil.

\begin{tabular}{|c|c|c|c|c|}
\hline \multirow{2}{*}{$\begin{array}{l}\text { Gesso } \\
\left.\text { (ton ha-1 }^{-1}\right)\end{array}$} & Outono & Inverno & Primavera & Verão \\
\hline & \multicolumn{4}{|c|}{ Matéria seca $\left(\mathrm{Kg} \mathrm{ha}^{-1}\right)$} \\
\hline 0,0 & $2191,1^{\text {ns }}$ & $190,6^{\text {ns }}$ & $755,3 b$ & $1914,8^{\text {ns }}$ \\
\hline 2,0 & 2371,4 & 213,6 & $1006,5 a$ & 2270,4 \\
\hline CV $(\%):$ & 18,83 & 24,84 & 20,39 & 19,71 \\
\hline DP: & 21,03 & 5,84 & 8,98 & 20,62 \\
\hline
\end{tabular}

DP: Desvio padrão. Médias seguidas por letras diferentes, dentro da coluna, diferem significativamente no nível de probabilidade de $5 \%$ pelo teste de Tukey. $n s$ = não significativo pelo teste $\mathrm{F}(\mathrm{p} \leq 0,05)$.

SORATTO \& CURSCIOL (2008), observaram que a aplicação de gesso proporcionou maior produção de matéria seca no primeiro ano de cultivo de aveia preta, com acréscimo de $705 \mathrm{~kg} \mathrm{ha}^{-1}$ o que representa um aumento de 15,6\% em relação ao tratamento sem aplicação. No entanto, CONTE et al. (2018) em Latossolo, também na região dos Campos de Cima da Serra do RS, encontraram aumento significativo na Rev. Ciênc. Agrovet., Lages, SC, Brasil (ISSN 2238-1171) 
produção de milho em doses acima das usadas neste experimento. Portanto, a dose utilizada neste experimento pode não ter sido suficiente para melhorias significativas na qualidade do solo para 0 desenvolvimento do campo nativo.

Em relação aos teores de nutrientes na parte aérea do campo nativo com a aplicação superficial de calcário no solo, houve diferença significativa apenas no período de outono e primavera (Tabela 4). A aplicação de calcário aumentou o teor de nitrogênio e potássio no tecido foliar das espécies presentes no campo nativo durante o período do outono e de cálcio na primavera. Os demais nutrientes e épocas não foram influenciados significativamente pela aplicação de calcário.

Tabela 4. Teores de nutrientes na parte aérea do campo nativo nas quatro estações do ano com aplicação superficial de calcário no solo.

Table 4. Nutrient content in the aerial part of the native field in the four seasons of the year with superficial application of lime in the soil.

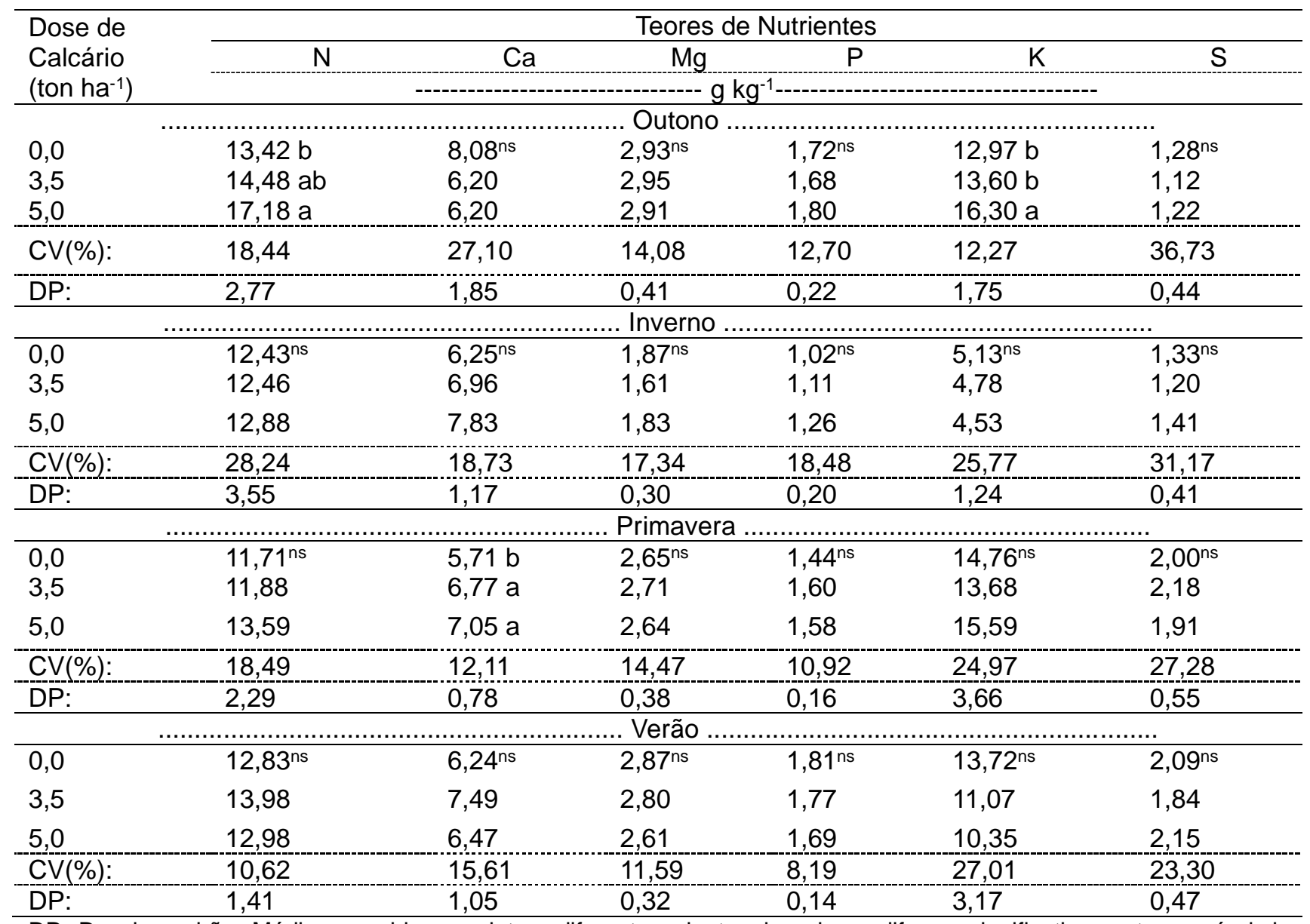

DP: Desvio padrão. Médias seguidas por letras diferentes, dentro da coluna, diferem significativamente no nível de probabilidade de $5 \%$ pelo teste de Tukey. ns = não significativo pelo teste $F(p \leq 0,05)$.

Conforme DOS SANTOS et al. (2016) a calagem, tanto na ausência quanto na presença de gesso, aumentou os teores de $\mathrm{N}$ nas folhas de sorgo, em consequência da elevação do pH na camada superficial, que proporcionou maior mineralização de $\mathrm{N}$ orgânico do solo e, promoveu efeito quadrático na produção de matéria seca do sorgo. Portanto, o efeito da aplicação de calcário na mineralização da matéria orgânica pode ter sido mais intenso no primeiro período avaliado após a aplicação, ou seja, outono. Este efeito pode ter sido reduzido nos períodos subsequentes avaliados.

O aumento do cálcio na parte aérea do campo nativo nas parcelas com aplicação de calcário, apenas na primavera, é atribuído a maior necessidade das espécies para essa estação do ano, com isso aumentando o teor deste macronutriente no tecido foliar. HERINGER \& JACQUES (2002) observaram um aumento nos teores de Ca no período da primavera. Os valores obtidos são similares aos encontrados por estes autores para campo nativo no município de André da Rocha - RS.

Em relação a aplicação superficial de gesso, houve diminuição no teor de Magnésio (Mg) das plantas do campo nativo quando houve aplicação do mesmo (Tabela 5). Os teores dos demais nutrientes nas diferentes épocas não foram afetados pela aplicação de gesso na superfície do campo nativo. 
A aplicação de gesso agrícola na superfície do solo acarretou a lixiviação de Mg para camadas mais profundas do solo. Tais resultados estão de acordo com os obtidos anteriormente por CAIRES et al. (1998, 2002) e PAULETTI et al. (2014). Estes autores concluíram que o ocorrido da lixiviação foi similar ao resultado do presente trabalho. Ainda, relatam que o gesso aumenta a movimentação do $\mathrm{Mg}$ no solo, sendo pouco duradouro o seu efeito.

De acordo com MESQUITA et al. (2002), o gesso, que atua no fornecimento de S, também supre Ca ao sistema solo-planta, elevando as concentrações desse elemento na matéria seca das forragens. Isso, provavelmente, é decorrente do enraizamento mais profundo, proporcionado pelo gesso e calcário, permitindo maior absorção de $\mathrm{Ca}$ e $\mathrm{S}$ nas camadas mais profundas. No entanto, estes experimentos foram realizados com culturas de grãos com exigências nutricionais distintas do campo nativo. Portanto, são necessários mais trabalhos com diferentes doses de gesso agrícola para esclarecer seus benefícios a produção e qualidade do campo nativo.

Os resultados deste trabalho indicam que a aplicação de calcário, em doses superiores às recomendadas pode contribuir para aumento na produtividade do campo nativo do Bioma Mata Atlântica, principalmente em estações de maior escassez de oferta de forragem.

Tabela 5. Teores de nutrientes na parte aérea do campo nativo nas quatro estações do ano com aplicação superficial de gesso agrícola no solo.

Table 5. Nutrient contents in the aerial part of the native field in the four seasons of the year with superficial application of plaster in the soil.

\begin{tabular}{|c|c|c|c|c|c|c|}
\hline \multirow{3}{*}{$\begin{array}{l}\text { Dose de } \\
\text { Gesso agrícola } \\
\left(\text { ton } \mathrm{ha}^{-1}\right)\end{array}$} & \multicolumn{6}{|c|}{ Teores de Nutrientes } \\
\hline & $\mathrm{N}$ & $\mathrm{Ca}$ & $\mathrm{Mg}$ & $\mathrm{P}$ & $\mathrm{K}$ & $S$ \\
\hline & \multicolumn{6}{|c|}{ - } \\
\hline \multicolumn{7}{|c|}{ 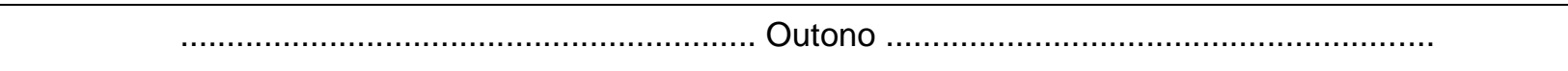 } \\
\hline 0,0 & $15,03^{\text {ns }}$ & $6,67^{\text {ns }}$ & $2,91^{\mathrm{ns}}$ & $1,75^{\text {ns }}$ & $14,72^{\text {ns }}$ & $1,25^{\text {ns }}$ \\
\hline 2,0 & 15,03 & 6,99 & 2,95 & 1,71 & 13,85 & 1,16 \\
\hline CV $(\%):$ & 18,44 & 27,10 & 14,08 & 12,70 & 12,27 & 36,73 \\
\hline DP: & 2,77 & 1,85 & 0,41 & 0,22 & 1,75 & 0,44 \\
\hline \multicolumn{7}{|c|}{ - } \\
\hline 0,0 & $13,54^{\text {ns }}$ & $7,35^{\text {ns }}$ & $1,99 \mathrm{a}$ & $1,20^{\text {ns }}$ & $5,30^{\text {ns }}$ & $1,45^{\text {ns }}$ \\
\hline 2,0 & 11,65 & 6,67 & $1,55 b$ & 1,05 & 4,33 & 1,17 \\
\hline CV $(\%):$ & 28,24 & 18,73 & 17,34 & 18,48 & 25,77 & 31,17 \\
\hline DP: & 3,55 & 1,17 & 0,30 & 0,20 & 1,24 & 0,41 \\
\hline \multicolumn{7}{|c|}{ 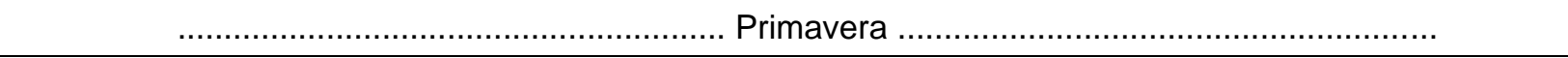 } \\
\hline 0,0 & $12,29^{\text {ns }}$ & $6,47^{\text {ns }}$ & $2,77^{\text {ns }}$ & $1,54^{\mathrm{ns}}$ & $15,50^{\text {ns }}$ & $1,87^{\text {ns }}$ \\
\hline 2,0 & 12,48 & 6,56 & 2,57 & 1,53 & 13,85 & 2,18 \\
\hline CV $(\%):$ & 18,49 & 12,11 & 14,47 & 10,92 & 24,97 & 27,28 \\
\hline DP: & 2,29 & 0,78 & 0,38 & 0,16 & 3,66 & 0,55 \\
\hline \multicolumn{7}{|c|}{ 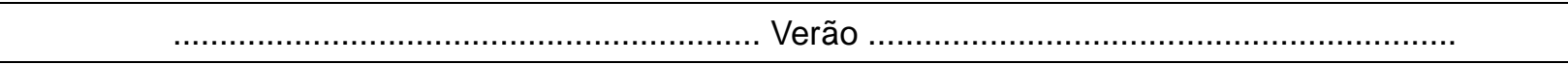 } \\
\hline 0,0 & $13,33^{\text {ns }}$ & $6,39^{\text {ns }}$ & $2,85^{\text {ns }}$ & $1,77^{\mathrm{ns}}$ & $11,17^{\text {ns }}$ & $1,97^{\text {ns }}$ \\
\hline 2,0 & 13,21 & 7,07 & 2,67 & 1,74 & 12,27 & 2,08 \\
\hline CV $(\%):$ & 10,62 & 15,61 & 11,59 & 8,19 & 27,01 & 23,30 \\
\hline DP: & 1,41 & 1,05 & 0,32 & 0,14 & 3,17 & 0,47 \\
\hline
\end{tabular}

DP: Desvio padrão. Médias seguidas por letras diferentes, dentro da coluna, diferem significativamente no nível de probabilidade de $5 \%$ pelo teste de Tukey. $n s=$ não significativo pelo teste $F(p \leq 0,05)$.

\section{CONCLUSÃO}

A utilização de calcário, na dose $\left(5,0 \mathrm{t} \mathrm{ha}^{-1}\right)$ para alcançar $75 \%$ de saturação por bases, ocasionou aumento da produtividade das pastagens nativa, principalmente nos períodos de maior escassez de 
forragem, no qual é compreendido o outono, inverno e parte da primavera.

A gessagem influenciou na lixiviação de Mg no solo. Já a calagem na dosagem mais alta, refletiu no teor de Ca foliar no período da primavera.

\section{REFERÊNCIAS}

ARAÚJO B. 2017 A importância da correção de solo ligada a calcário e gesso. Disponível em: <https://ruralcentro.com.br/analises/a-importancia-da-correcao-de-solo-ligada-a-calcario-e-gesso-4754>. Acesso em: 10 out. 2020.

AVILA MR et al. 2019. Botanical composition of a natural rangeland overseeded with annual ryegrass under $\mathrm{N}$ fertilization. Scientia Agropecuaria 10: 303-305.

BOLDRINI II. 2009. A flora dos campos do Rio Grande do Sul. In: PILLAR VD. (Ed.). Campos sulinos: conservação e uso sustentável da biodiversidade. Brasília: MMA. p.63-77.

CAIRES EF et al. 1998. Alterações de características químicas do solo e resposta da soja ao calcário e gesso aplicados na superfície em sistema de cultivo sem preparo do solo. Revista Brasileira de Ciência do Solo 22: 27-34.

CAIRES EF \& GUIMARAES AM. 2016. Recomendação de gesso para solos sob plantio direto da região Sul do Brasil. In: FertBio 2016. Resumos... Goiânia. p.1.

CAIRES EF et al. 2002. Correção da acidez do solo, crescimento radicular e nutrição do milho de acordo com a calagem na superfície em sistema plantio direto. Revista Brasileira de Ciência do Solo 26: 1011-1022.

CARVALHO PCF et al. 1998. Potencial produtivo do campo nativo do Rio Grande do Sul. In: PATIÑO HO. (Ed.). Suplementação de ruminantes em pastejo. Porto Alegre: UFRGS. p.1-20.

CONTE ED et al. 2018. Rates of Agricultural Gypsum in Soil Under No-tillage System With Surface Lime in the Southern of Brazil. Journal of Agricultural Science 10: 544.

CONTE ED et al. 2016. Boas práticas de manejo de solo, plantas daninhas e agricultura de precisão. 1.ed. Caxias do Sul: EDUCS.

CORSI M \& SILVA RTL. 1985. Fatores que afetam a composição mineral de plantas forrageiras. In: SIMPÓSIO DE NUTRIÇÃO DE BOVINOS. Resumos... Piracicaba: FEALQ. p.1-14.

COSTA NL et al. 2012. Resposta de Brachiaria brizantha cv. Xaraés a níveis de calagem. PUBVET 6: 1-10.

CQFS - RS/SC. 2016. Comissão de Química e Fertilidade do Solo - RS/SC. Manual de calagem e adubação para os Estados do Rio Grande do Sul e Santa Catarina. 11.ed. Sociedade Brasileira de Ciência do Solo - Núcleo Regional Sul. 376 p. (Manual).

DOS SANTOS MP et al. 2016. Importância da calagem, adubações tradicionais e alternativas na produção de plantas forrageiras: revisão. PUBVET 10: 1-12.

ELEJALDE DAG et al. 2012. Quality of the forage apparently consumed by beef calves in natural grassland under fertilization and oversown with cool season forage species. Revista Brasileira de Zootecnia 41: 1360-1368.

FERREIRA ET et al. 2011. Terminação de novilhos de corte Angus e mestiços em pastagem natural na região da Campanha do RS. Revista Brasileira de Zootecnia 40: 2048-2057.

HERINGER I \& JACQUES AVA. 2002. Qualidade da forragem de pastagem nativa sob distintas alternativas de manejo. Pesquisa Agropecuária Brasileira 37: 399-406.

IBGE. 2020. Instituto Brasileiro de Geografia e Estatística. Contas de Extensão de Ecossistema. Disponível em: <https://sidra.ibge.gov.br/tabela/7335\#resultado>. Acesso em: 13 jan. 2021.

MALAVOLTA E et al. 1997. Avaliação do estado nutricional das 284 plantas: princípios e aplicações. 2.ed. Piracicaba: Potafos. 319p.

MESQUITA EE et al. 2002. Efeitos de métodos de estabelecimento de braquiária e estilosantes e de doses de calcário, fósforo e gesso sobre alguns componentes nutricionais da forragem. Revista Brasileira de Zootecnia 31: 2186- 2196.

MOREIRA FB et al. 2001. Avaliação de aveia preta cv lapar 61 submetida a níveis crescentes de nitrogênio em área proveniente de cultura de soja. Acta Scientiarum Animal Sciences 23: 815-821.

NABINGER $C$ et al. 2009. Produção animal com base no campo nativo: aplicações de resultados de pesquisa. In: PILLAR VD. (Ed.). Campos sulinos: conservação e uso sustentável da biodiversidade. Brasília: MMA. p.175-198.

PAULETTI V et al. 2014. Efeitos em longo prazo da aplicação de gesso e calcário no sistema de plantio direto. Revista Brasileira de Ciência do Solo 38: 495-505.

SILVA J \& QUEIROZ AC. 2006. Analise de alimentos: método químico e biológico. 3.ed. Viçosa: UFV. 235p.

SORATTO RP \& CRUSCIOL CAC. 2008. Produção de fitomassa e acúmulo de nutrientes pela aveia-preta em função da aplicação de calcário e gesso em superfície na implantação do sistema plantio direto. Ciência Rural 38: 928-935.

STELLA LA et al. 2013. Melhoramento produtivo do campo nativo através da adubação mineral. In: 3 Simpósio de sustentabilidade e Ciência Animal. Resumos... Pirassununga: USP. P 1-3.

TEDESCO MJ et al. 1995. Análise de solo, plantas e outros materiais. Porto Alegre: UFRGS. 174p. (Boletim Técnico 5).

WEISSHEIMER M. 2015. Os campos do Sul vão virar uma grande lavoura de soja? Porto Alegre: Sul21. Disponível em: <https://www.sul21.com.br/entrevistas-2/2015/06/os-campos-do-sul-vao-virar-uma-grande-lavoura-de-soja/>. Acesso em: 22 out. 2020. 